\title{
PROPOSTA DE HABITAÇÃO DE INTERESSE SOCIAL PARA A COMUNIDADE ALTO DA ALEGRIA, CHÃ PRETA-AL.
}

\author{
Benedito Soares de Vasconcelos Neto ${ }^{1}$ \\ Débora de Barros Cavalcanti Fonseca
}

\begin{abstract}
RESUMO
O presente trabalho apresenta uma proposta de habitação de interesse social para a Comunidade Alto da Alegria, localizada no Município de Chã Preta-AL realizada no âmbito de um Trabalho Final de Graduação que se materializou em uma maquete com a proposta de espaço urbano. $O$ trabalho partiu de uma caracterização sócio-espacial da área, onde através de processos participativos (visitas, entrevistas e desenho participativo) buscou interagir com as famílias para saber, ouvir e analisar suas necessidades em termos de unidade habitacional e de espaço urbano e assim nortear a elaboração das propostas. Este trabalho projeta para uma comunidade de escassos recursos e em situação de pobreza uma alternativa espacial, ouvindo seus desejos e necessidades, utilizando-se da arquitetura e do urbanismo para promover qualidade de vida para essas famílias, buscando proporcionar mais conforto e dignidade.
\end{abstract}

PALAVRAS-CHAVE: Habitação social. Comunidade. Necessidades habitacionais.

\section{INTRODUÇÃO}

Todo ser humano tem direito à moradia digna e sonha em possuir sua casa provida das melhores condições físicas possíveis, como assegura a Declaração Universal dos Direitos Humanos (MEDEIROS, 2007).

Com condições dignas para morar, o cidadão sente-se inserido no meio social, reconhecido perante a sociedade. Segundo Medeiros (2007), em algumas realidades brasileiras, a falta de uma moradia digna, confortável e salubre, só torna

\footnotetext{
${ }^{1}$ Centro Universitário CESMAC, netovasconcelos10@hotmail.com
} 


\section{Revista Nacional de}

Gerenciamento de Cidades

mais difícil a árdua batalha diária da população. Muitas vezes, as moradias não são regularizadas, o que não dá direito ao morador de ter um endereço, tornando-o assim cidadão de segunda classe pois nem consegue receber uma correspondência.

Hoje o modelo nacional de projetos de habitação popular predefine um único programa de necessidades engessado em diversos paradigmas, como por exemplo, o custo, produzindo residências onde os moradores são obrigados a se adaptarem à nova casa, e não o inverso.

Esse modelo de moradia não proporciona escolha ao morador. Atualmente o programa de necessidades é definido previamente, apesar de cada família possuir composição e necessidades distintas (ARAVENA, 2012). Portanto, quando o arquiteto é encarregado de propor um projeto de habitação popular para determinada comunidade, não deveria abdicar da necessidade de ouvir os moradores. É preciso que o profissional se insira na comunidade, sinta a necessidade de cada família, para que o projeto resultante seja adaptável a todos os moradores, proporcionando-lhes a liberdade de ampliar suas casas de acordo com cada necessidade, para melhor conforto e qualidade de vida dos moradores.

A comunidade alvo desta experiência foi a Comunidade Alto da Alegria onde residem atualmente 68 famílias, está situada a oeste da cidade de Chã Preta, município do Agreste Alagoano. Segundo informações obtidas na área, a comunidade originou-se em 2000 após ocupação de um terreno que a Prefeitura havia comprado para a construção de habitações populares, mas que nunca foram construídas.

\section{APRESENTAÇÃO DA EXPERIÊNCIA E SEUS OBJETIVOS}

O presente artigo apresenta o relato de uma experiência de elaboração de um Trabalho Final de Graduação que se propôs a projetar habitação de interesse social para a Comunidade Alto da Alegria, localizada no Município de Chã Preta-AL. O 


\section{Revista Nacional de}

objetivos da experiência foram: i) destacar a importância social do arquiteto e urbanista na concepção do projeto de habitação popular; ii) mostrar a importância desse profissional para o desenvolvimento sócio-espacial de uma comunidade, onde é preciso que ele se insira para compreender a dinâmica da vida dos moradores, como a comunidade funciona e as necessidades das famílias, visando um projeto adequado à população e iii) produzir para a Comunidade Alto da Alegria, um modelo de habitação baseado nas necessidades de cada família e organizar as habitações em um traçado urbano mais adequado.

Figura 01: Vista geral da Comunidade

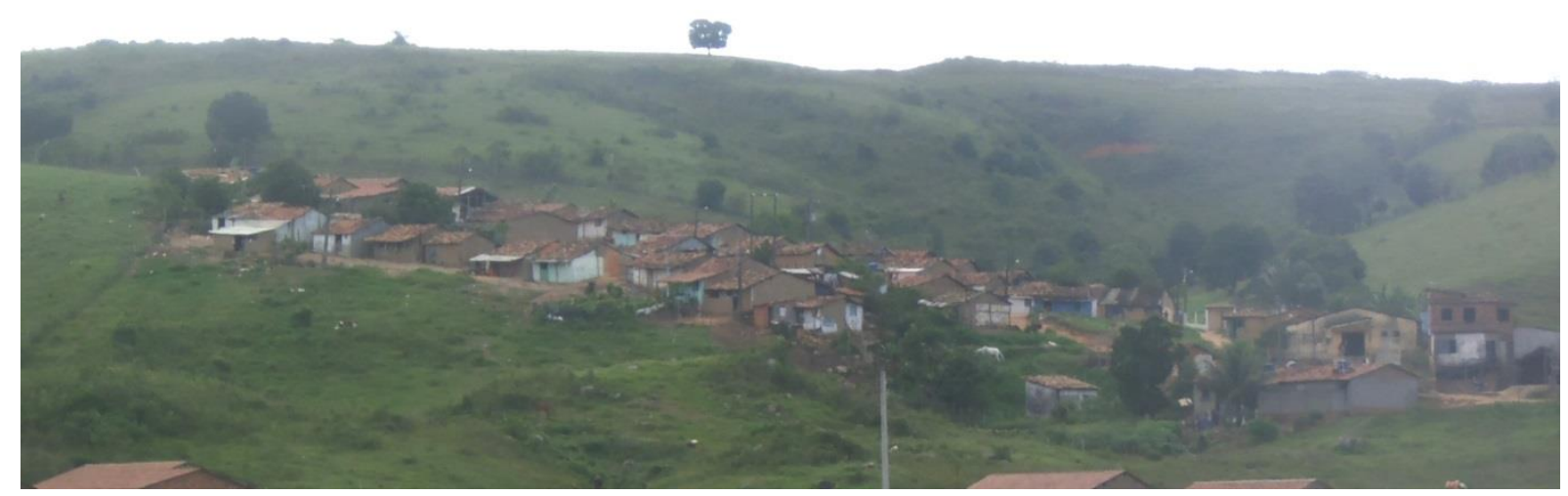

Fonte: VASCONCELOS NETO, 2014.

\section{METODOLOGIA / MÉTODO DE ANÁLISE}

Para iniciar o processo de projetação desenvolvido nesta experiência, desenvolveu-se junto com a comunidade um processo de desenho participativo, com o objetivo de se conhecer melhor seus desejos e para se chegar o mais próximo possível do ideal em termos de programa de necessidades da habitação e do espaço urbano.

O processo foi dividido em duas etapas. A primeira etapa teve o objetivo de identificar o programa de necessidades ideal da unidade habitacional, e para isso foi 


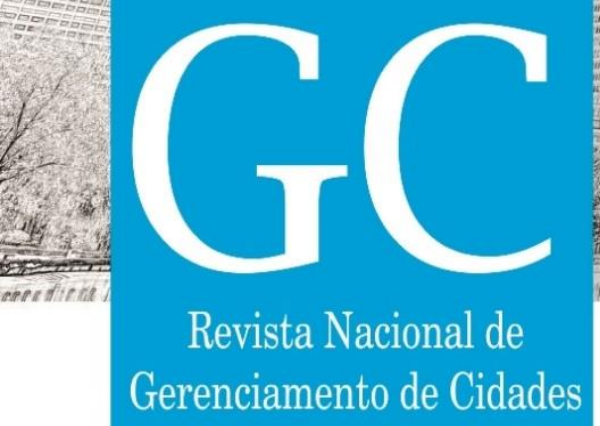

aplicada a metodologia de desenho participativo, onde foram utilizados quadrados coloridos de papel que representavam cada ambiente da casa. A cor verde representava a varanda, a cor vermelha a sala (estar e jantar), a azul simbolizava o quarto, a amarela o banheiro, a cor laranja a cozinha e a cor preta a área de serviço.

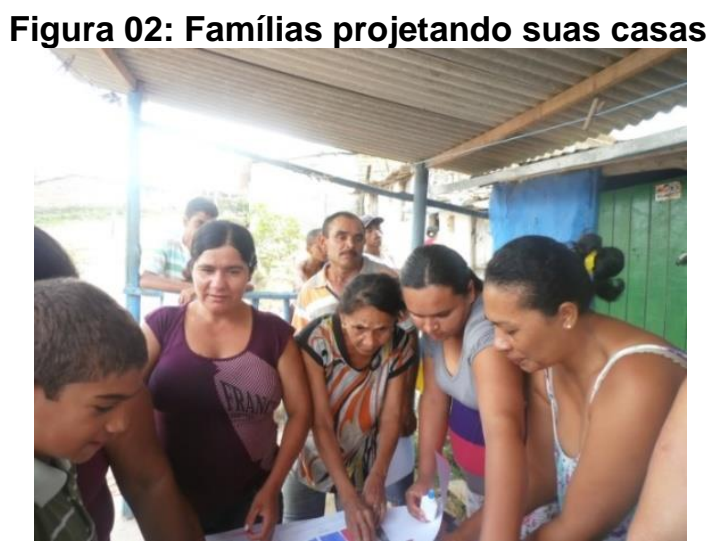

Fonte: VASCONCELOS NETO, 2014.

Figura 03: Sr. José Duarte da Costa, partícipe do desenho participativo

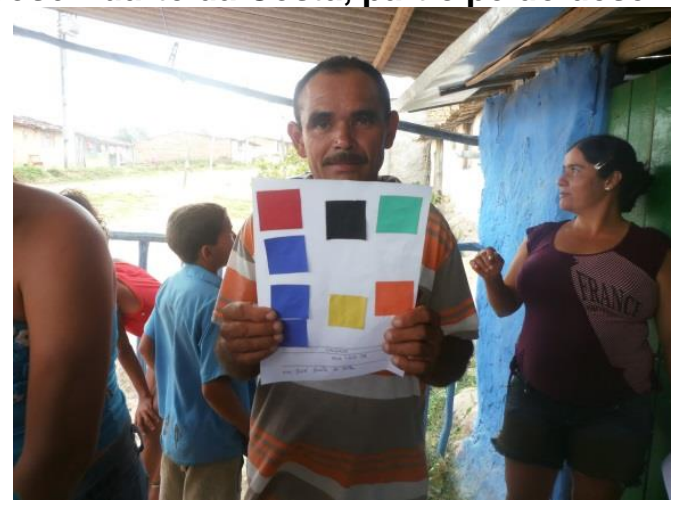

Fonte: VASCONCELOS NETO, 2014

Os moradores receberam uma folha para que cada um montasse com os quadrados coloridos sua casa ideal, fazendo assim uma espécie de planta baixa colorida. Participaram dessa experiência 18 famílias. Foi um processo que envolveu todo o grupo familiar, que de forma dinâmica, pôde expressar seus desejos e necessidades habitacionais. Diante da impossibilidade de construir 18 projetos diferentes, optou-se, portanto, em realizar uma síntese das diferentes disposições 


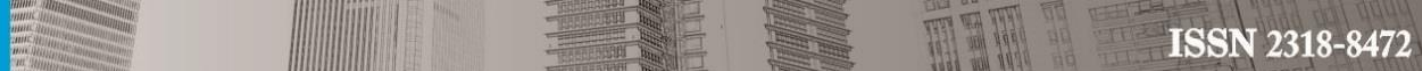

จ. $03, n .18,2015$

\section{Revista Nacional de}

Gerenciamento de Cidades

em uma única proposta que atendesse a maior parte das demandas e desejos. $\mathrm{Na}$ Figura 03 apresenta-se a síntese realizada dos projetos elaborados por cada família.

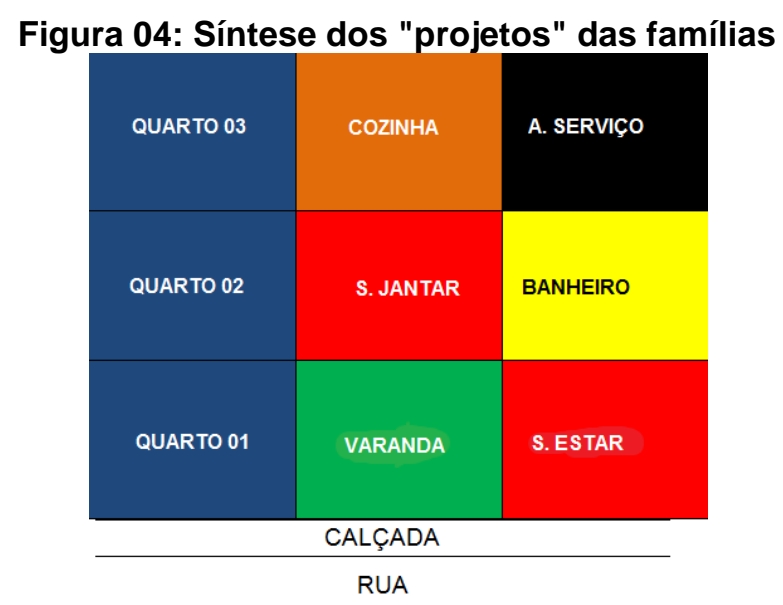

Fonte: VASCONCELOS NETO, 2014.

$\mathrm{Na}$ segunda etapa, buscou-se compreender os desejos com relação ao espaço urbano. Foi apresentada uma maquete de como a comunidade é atualmente, e através dela os moradores puderam idealizar o que gostariam que fosse modificado e acrescentado ao espaço onde vivem.

Eles afirmaram apreciarem a organização territorial atual, porém, ressaltaram que se fosse para o bem comum poderia haver modificações no espaço atual, tais como a relocação de lotes. Também expuseram o desejo de ter um monumento com uma imagem religiosa do Padre Cícero e uma praça arborizada na comunidade, além de manter os três lotes já existentes com casas em alvenaria que foram construídas pela administração pública municipal em 2008, e reformar a escola existente na comunidade.

\section{RESULTADOS}




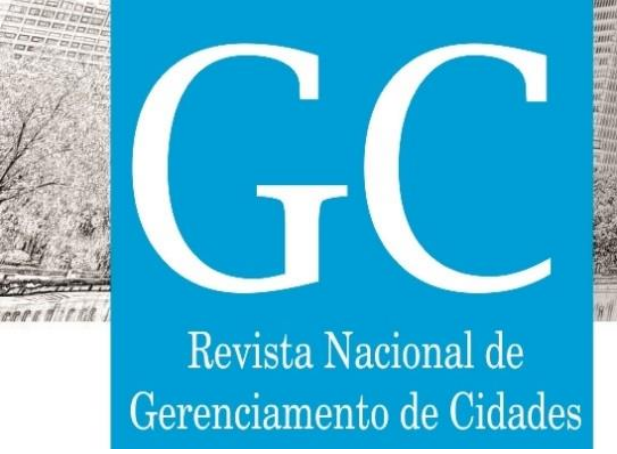

Com os resultados obtidos através de visitas in loco e a aplicação do desenho participativo, concluiu-se que o programa de necessidades das residências da Comunidade Alto da Alegria deveria conter varanda, sala de estar, sala de jantar, três quartos, banheiro, cozinha e área de serviço.

Para a proposta de espaço urbano buscou-se manter as características espaciais atuais do assentamento, seguindo a posição já existente dos lotes e das ruas. Na proposta, os lotes têm testada frontal de 8,00m e 16,00m de profundidade, que resulta em uma área de $128 \mathrm{~m}^{2}$. A proposta resultou em um assentamento com 72 lotes.

Figura 05: Proposta de loteamento

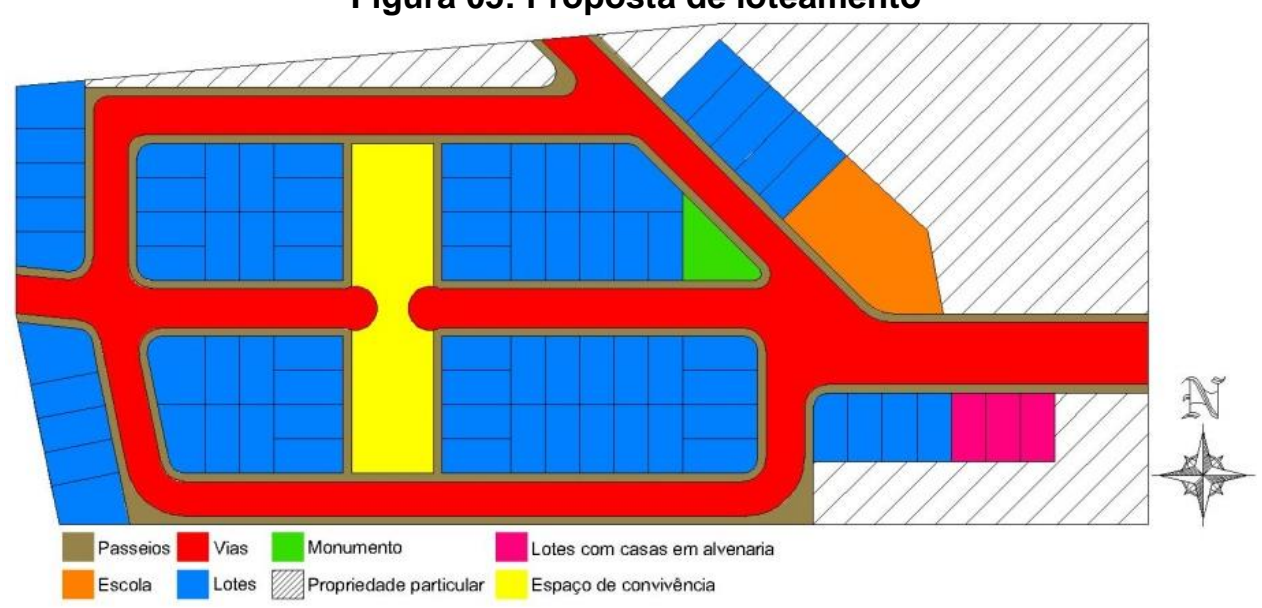

Fonte: VASCONCELOS NETO, 2014.

$\mathrm{Na}$ proposta urbanística buscou-se criar um espaço de convivência, permitindo que o espaço não seja um empecilho para o desenvolvimento social daquela comunidade. Esta proposta foi baseada nas entrevistas e oficinas realizadas com a comunidade.

A proposta de habitação, de acordo com o programa de necessidades, alcançou uma área de $60 \mathrm{~m}^{2}$ que contempla uma varanda, três quartos, sala de estar e jantar, um banheiro, cozinha e área de serviço, conforme definido pelos próprios moradores. 


\section{Revista Nacional de}

Gerenciamento de Cidades

O projeto foi desenvolvido também sob a ótica defendida pelo arquiteto chileno Alejandro Aravena, que defende que seja entregue às famílias uma boa casa para que elas possam com o tempo ampliá-las.

$O$ projeto seguiu o pressuposto de que se permitisse flexibilidade para ser ampliado com facilidade pelas famílias, reduzindo seus custos da ampliação. A distribuição dos cômodos no projeto foi pensada de forma que em um primeiro momento seja financiada e executada uma casa com $47 \mathrm{~m}^{2}$ (média dos valores das casas do Programa habitacional Minha Casa Minha Vida), sem o terceiro quarto (azul) e a varanda (verde), que seriam posteriormente construídos pelos próprios moradores.

Figura 08: Área para ampliação pelos próprios moradores

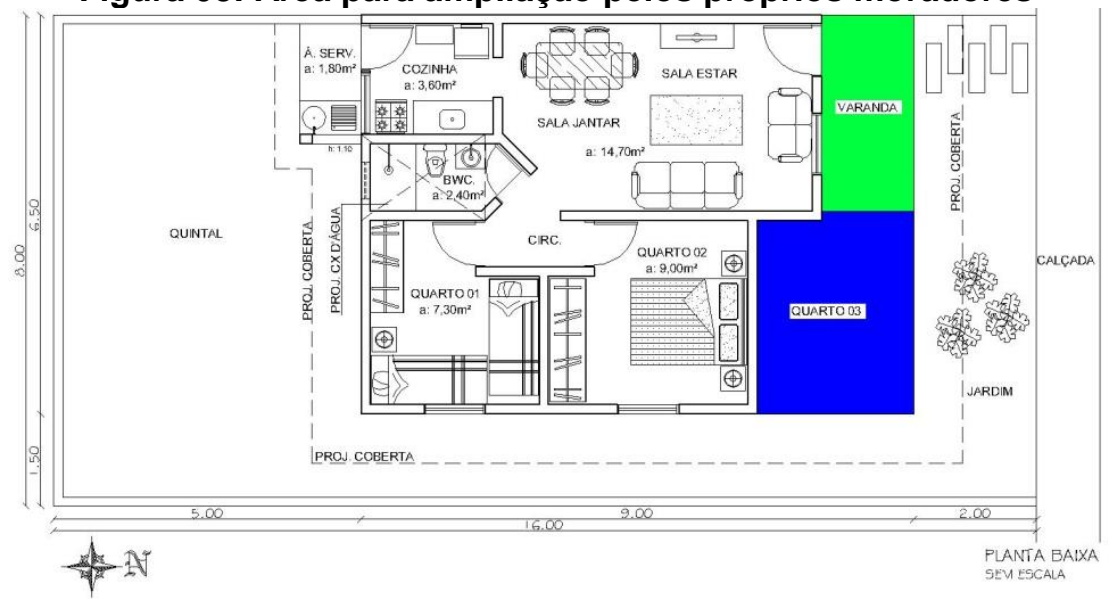

Fonte: VASCONCELOS NETO, 2014.

No projeto da casa não se buscou desenvolver um traçado inédito, mas sim um projeto que captasse a essência das necessidades de cada família da Comunidade Alto da Alegria e que pudesse ser construído por eles próprios ou pela mão de obra local. 


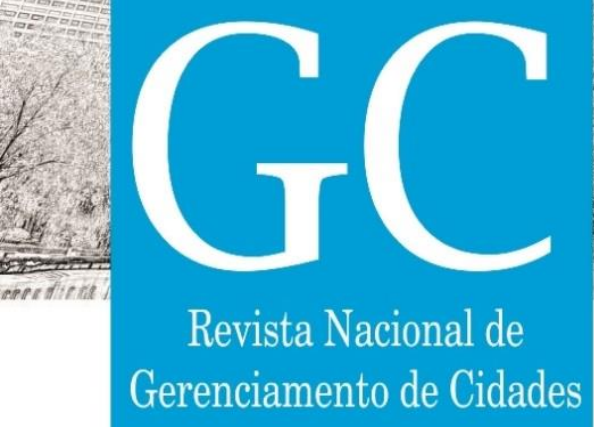

Figura 09: Perspectiva habitação

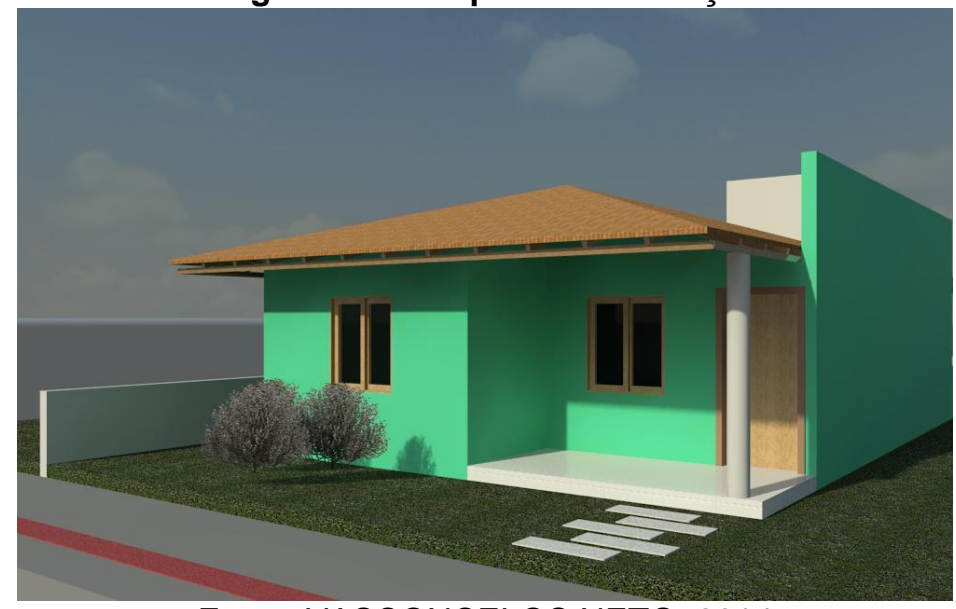

Fonte: VASCONCELOS NETO, 2014.

Quando foi apresentada a proposta de habitação, a primeira curiosidade das famílias foi se na casa havia banheiro. Esse interesse se deve ao fato de que na Comunidade não existe casa provida de banheiro.

O encanto por uma moradia que estaria suprindo suas necessidades, deixou-os satisfeitos com o resultado, pois para eles a proposta habitacional os alimentava de esperança por um futuro melhor.

O olhar das crianças na Figura 08 a seguir, traduz o que esse momento significou para toda a Comunidade. Olhares de esperança, de sonho, de desejos e de perceber a possibilidade de que esses anseios poderiam se tornar realidade. Para eles na maquete da casa estava o começo da materialização de muitos sonhos. 
